\title{
Supporting the Quality of Learning Objects Through Their Ranking Visualization
}

\author{
doi:10.3991/ijet.v4s1.863 \\ E.M. Morales Morgado, D.A. Gómez Aguilar, F.J. García Peñalvo, R. Therón Sánchez \\ University of Salamanca, Salamanca, Spain
}

\begin{abstract}
The quality of Learning Objects (LOs) is currently being promoted by certain tools which consider specific criteria for their evaluation; however, there is no existing methodology that considers both the value assigned to the $\mathrm{LO}$ itself and the percentage related to the number of evaluators who have compared the quality of resources. As in the case of various products offered through the Internet backed by an assessment of users in a unified ranking, the purpose of this paper is to suggest a proposal for the automated assessments of experts who can clearly see the best or worst aspects in LO quality.
\end{abstract}

Index Terms_Learning Objects, Evaluation, E-learning.

\section{INTRODUCTION}

The quality of educational resources needs to be measured through an instrument that will reflect to what extent the resource in question fulfills specific quality criteria. In the case of LOs there are diverse tools that consider different quality criteria and assessment rubrics. Within those criteria there are technical and pedagogical issues that are valued by experts and users individually in order to make the necessary improvements, but those results are often not visible to users who are not able to compare what subject has been rated better or worse and why. With this situation in mind, the aim of this paper is to propose a methodology for ranking learning objects based on a tool that considers specific types of LOs.

On this basis, the second section presents the various LO types suggested for evaluating different kinds of granularity level quality. The third section presents the evaluation tool HEODAR (Herramienta de Evaluación de Objetos Didácticos de Aprendizaje Reutilizables/Reusable Learning Objects Assessment Tool) and a proposal about how this could be advantageous to users by providing a ranking methodology that allows them to view and select LOs according to their quality. Finally, we present our conclusions and future work.

\section{Defining the Type Of LEARning OBJect to EVALUATE}

The development of standards for e-learning and the characteristics of LOs offer new possibilities for managing educational resources. There are many possibilities for knowledge management to support teaching and learning processes, through e-learning systems, such as knowledge delivery and student evaluation of courses, etc. [1] [7]. However, according to the LO characteristics and the capabilities of the standards it is necessary to consider how to manage the quality of LOs by taking into account their characteristics.
In order to decide what to manage in an LO management system we must define the type of object to be treated according to its granularity level, how it is managed and who is involved in its management.

In light of the above, this proposal suggests managing and evaluating LOs according to their granularity level. The levels proposed by IEEE LOM [4] are broad and do not present an educational structure for their use. In this situation, in order to know what type of object should be assessed and managed, a more specific definition of the granularity levels of this standard must be undertaken.

These groups of LOs that will make up new educational units at various levels should be classified to know specifically what type of LO is being managed. Considering the level of granularity proposed by IEEE LOM, this proposal suggests the following classification [8].

- Level 1: The smallest level of granularity, e.g, a photo, a video, etc.

- Level 2: A lesson with a specific learning objective, considering a specific kind of contents (data and concepts, procedure and processes, reflection and attitude), which can be formed by a group of level 1 LOs. Practice and evaluation activities can also be considered (optional).

- Level 3: A learning module composed of a set of lessons (level 2 LOs) with a minimum of two or three kinds of contents (data and concepts, procedure and process, principles). Practice and evaluation activities can also be considered (optional).

- Level 4: A learning course composed of a set of modules (level 3 LOs) with a minimum of two or three kinds of contents (data and concepts, procedure and process, principles). Practice and evaluation activities can also be considered (optional).

The LO definition is a key issue in order to establish specific quality criteria. To define an evaluation instrument, we decided to consider the minimal unit of learning as our Level 2 because we believe it fulfills the requisites for the main idea of the $\mathrm{LO}$ concept.

Accordingly, we have defined what kind of quality criteria must be considered for LO evaluation, but first our definition of LO quality must be given. Taking into account certain quality definitions, quality itself and quality educational resources, we define LO quality as the resources that fulfill the characteristics of achieving educational goals in an effective way and also as the 
resources that can be reused and managed in a suitable way.

Given the various LO definitions in the literature and the various levels of granularity proposed by IEEE LOM, it is possible to find LOs with the same size but different components and instructional design [12]. In order to evaluate an item, whatever it is, it is always necessary to know its characteristics and then apply the criteria, metrics and tools necessary.

The definition of the components for each level of granularity suggested in this proposal serves as a basis on which to define specific criteria to assess whether or not LOs meet the quality requirement. These components ensure that the design of LOs fulfills the minimum instructional requirements needed to consider the LO as a minimum unit through which a specific learning goal can be achieved.

To provide the criteria for evaluating the object from different points of view it is important to classify them into categories that define the evaluation framework

\section{LEARNING OBJECTS EVALUATION INSTRUMENT FOR EXPERTS}

The HEODAR tool has thus been designed taking into account a broad variety of quality criteria for evaluating LOs from pedagogical and technical points of view [10], which is the result of reviewing various proposals for educational resources assessment as well as a comparative analysis with the LO assessment tool LORI [11].

The educational category is addressed to assessing aspects associated with the user (psychological significance) and the curriculum (logical significance). On this basis, we propose criteria for evaluating educational aspects through the "psychopedagogical" and "teaching curriculum" categories. Moreover, we also propose criteria for evaluating aspects of interface design and navigation [10].

The purpose of the educational criteria is to assess a range of educational issues and must be present in any educational contents to promote learning, whether in matters relating to students or the curriculum. As a result we have designed a tool that aims to assess the contents from two angles: psycho-curricular and teaching.

In the psychopedagogical category, the criteria are aimed at evaluating the psychological aspects; for this reason, the term "psychopedagogical" has been used. The criteria have been defined on this basis: Capable of motivation (attractive and original presentation, provides relevant information, etc.), adaptation to the audience, interactivity and creativity (Figure 1).

In the curricular teaching category the approaches are associated with logical significance, i.e. whether the LO is appropriate for curriculum goals (Figure 2). Among these are: objectives (properly formulated, feasibility), contents (information that is correct, accurate, non-discriminatory; structuring of the material in a way appropriate to the objectives and characteristics of users), activities and methodology.

As regards the concept of usability, it refers to the ease with which specific users can employ the LO in specific contexts; therefore, it is subject to objective conditions that can be measured by different users, as well as subjective conditions in relation to the degree of user satisfaction with respect to the use of a resource. This concept is also applied to the Web characteristics as regards an adequate and efficient interface design.

The design of the LO is a very important factor in the evaluation of its quality. The LO can be very good in terms of contents and pedagogically well structured; however, if the interface design hinders interaction it may ultimately discourage users and reduce their attention level. Currently there is enough literature available to help make a proper web design and improve usability, from which different quality criteria can be obtained [2], [6], [13].

On this basis and in accordance with the principles of usability [13] we have established two basic aspects in the evaluation of LO interface design: content design and navigation design.

Interface design addresses the assessment of technical aspects associated with the aesthetic design of the LOs. Aspects to assess are: Text, Image, Animation, Multimedia, Audio, and Video. Each of these aspects presents specific criteria for evaluation (Figure 3).

Navigation design is focused on evaluating the organization of information in relation to the possibilities of accessing it through navigation (Figure 4). Based on [13], evaluation criteria associated with the home page and navigation are suggested.

To assess each of the criteria a range has been defined, as shown in Figure 2, which includes a numerical rating from 1 to 5 , five being the highest. There is also a "Don't know" option that can be used if the expert is not familiar with the criteria.

For this situation, we have defined a textual value because if it were numerical, the instrument would average it in with the other values, which would result in a very bad evaluation, which is not necessarily the case, thus reducing the value of the final quality assessment. [8] [9] [10].

Each of the criteria that are within a category should be evaluated on an individual basis, thus ensuring a more accurate and reliable result. After this assessment, the tool calculates the average that reflects the final value of the LO's quality.

Accordingly, the tool presents an item for "comments" in which the evaluator can make further comments not only on the object itself, but is also asked "if you consider that the object can be reused in other areas, give some examples." The responses are then analyzed through a qualitative assessment which summarizes the main ideas put forward and metadata are added as a description of its numerical quality. 


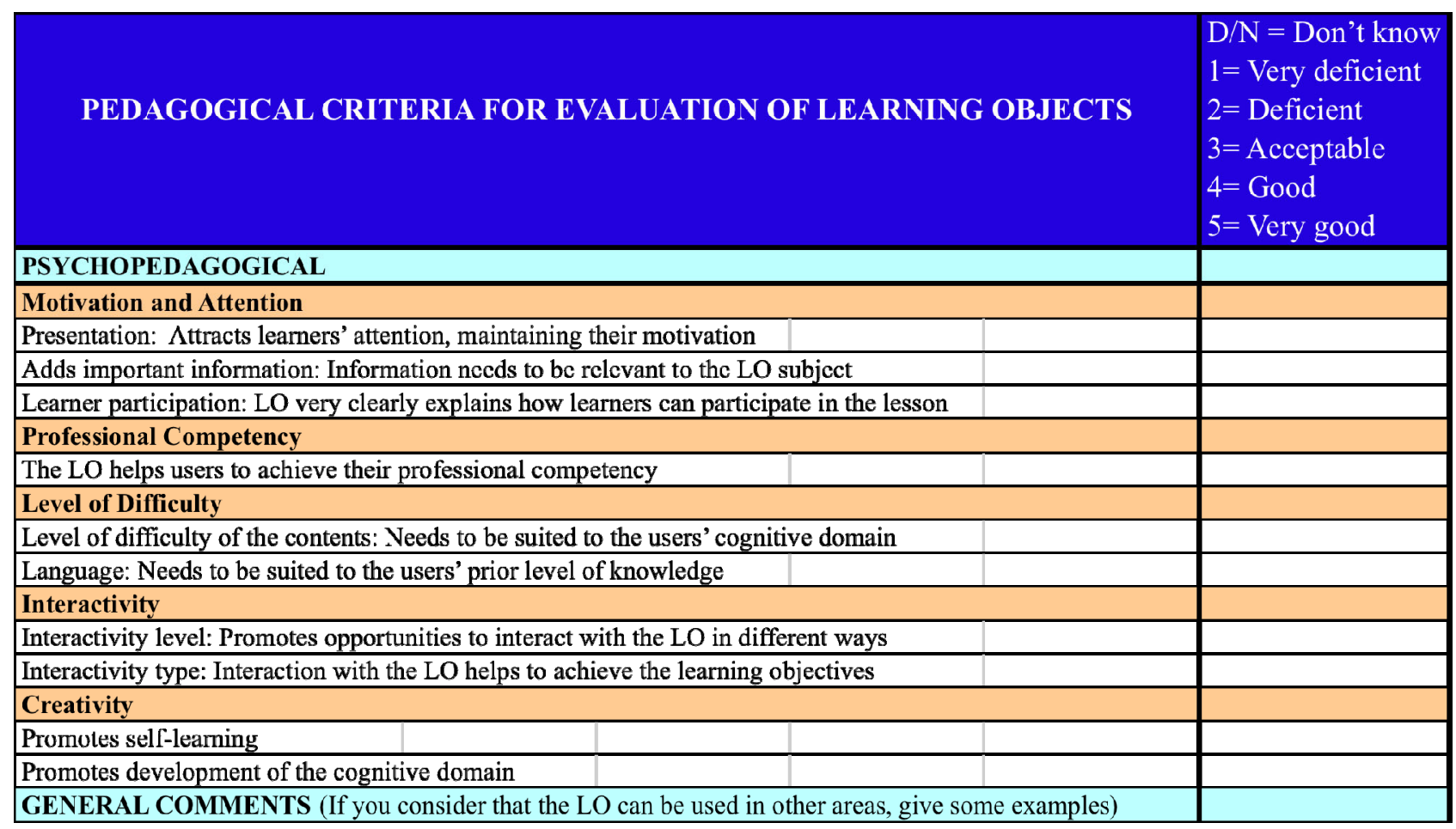

Figure 1. Psychopedagogical category for evaluating Los

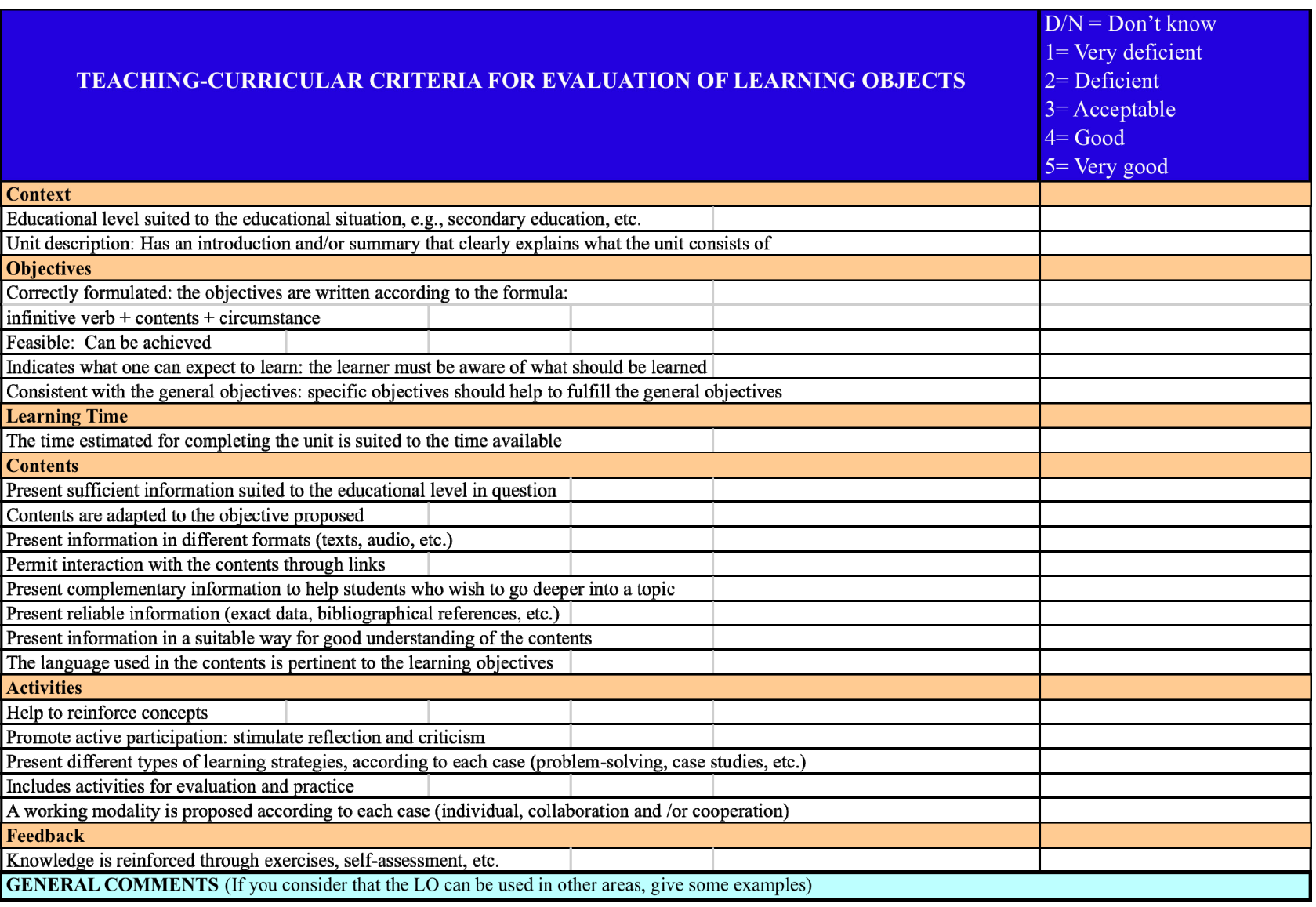

Figure 2. Teaching-Curricular category for evaluating Los 


\begin{tabular}{|c|c|c|}
\hline \multicolumn{2}{|c|}{ USABILITY CRTIERIA FOR EVALUATION OF LEARNING OBJECTS } & $\begin{array}{l}\mathrm{D} / \mathrm{N}=\text { Don't know } \\
\text { 1= Very deficient } \\
\text { 2= Deficient } \\
\text { 3= Acceptable } \\
\text { 4= Good } \\
\text { 5= Very good }\end{array}$ \\
\hline \multicolumn{3}{|l|}{ INTERFACE DESIGN } \\
\hline \multicolumn{3}{|l|}{ Text } \\
\hline \multicolumn{3}{|c|}{ Organized into short paragraphs, without breaking paragraphs or the } \\
\hline \multicolumn{3}{|c|}{ continuity of the ideas expressed in them } \\
\hline \multicolumn{3}{|c|}{ Uses hypertext to divide extensive information into multiple pages } \\
\hline \multicolumn{3}{|c|}{\begin{tabular}{|l|l|l|} 
Marks blocks of contents using titles or sections & \\
\end{tabular}} \\
\hline \multicolumn{3}{|c|}{ Uses capital letters for titles and headings or to highlight important bits of text } \\
\hline \multicolumn{3}{|c|}{ Avoids underlining when there are no links } \\
\hline \multicolumn{3}{|c|}{\begin{tabular}{|l|l|} 
Font is legible and of a suitable size \\
\end{tabular}} \\
\hline \multicolumn{3}{|c|}{ Colors and font types contribute information in themselves } \\
\hline \multicolumn{3}{|c|}{\begin{tabular}{|l|l|l|l|l} 
No spelling errors \\
\end{tabular}} \\
\hline \multicolumn{3}{|l|}{ Images } \\
\hline \multicolumn{3}{|l|}{ Clarify textual information } \\
\hline \multicolumn{3}{|l|}{ Not superfluous } \\
\hline \multicolumn{3}{|l|}{ Animations } \\
\hline \multicolumn{3}{|l|}{ Justified and not used in excess } \\
\hline \multicolumn{3}{|c|}{ Attract the attention of the user in order to highlight important things } \\
\hline \multicolumn{3}{|l|}{ Do not take long to load } \\
\hline \multicolumn{3}{|c|}{ Avoids animations that are presented in one cycle without stopping } \\
\hline \multicolumn{3}{|l|}{ Multimedia } \\
\hline \multicolumn{3}{|c|}{ Uses multimedia justifiably, only when necessary } \\
\hline \multicolumn{3}{|c|}{ When loading time takes more than 2 seconds, this is indicated in parentheses } \\
\hline \multicolumn{3}{|l|}{ Audio } \\
\hline \multicolumn{3}{|c|}{ Uses sound only when necessary (optional for the user) } \\
\hline \multicolumn{3}{|c|}{ Gives information on the sound file characteristics before loading (size, types of connection, etc.) } \\
\hline \multicolumn{3}{|c|}{ Vídeo } \\
\hline \multirow{2}{*}{\multicolumn{2}{|c|}{$\begin{array}{l}\text { Used justifiably, only when it can contribute something } \\
\text { Both image and audio are clear }\end{array}$}} & \\
\hline & & \\
\hline
\end{tabular}

Figure 3. Interface-Design category for evaluating LOs

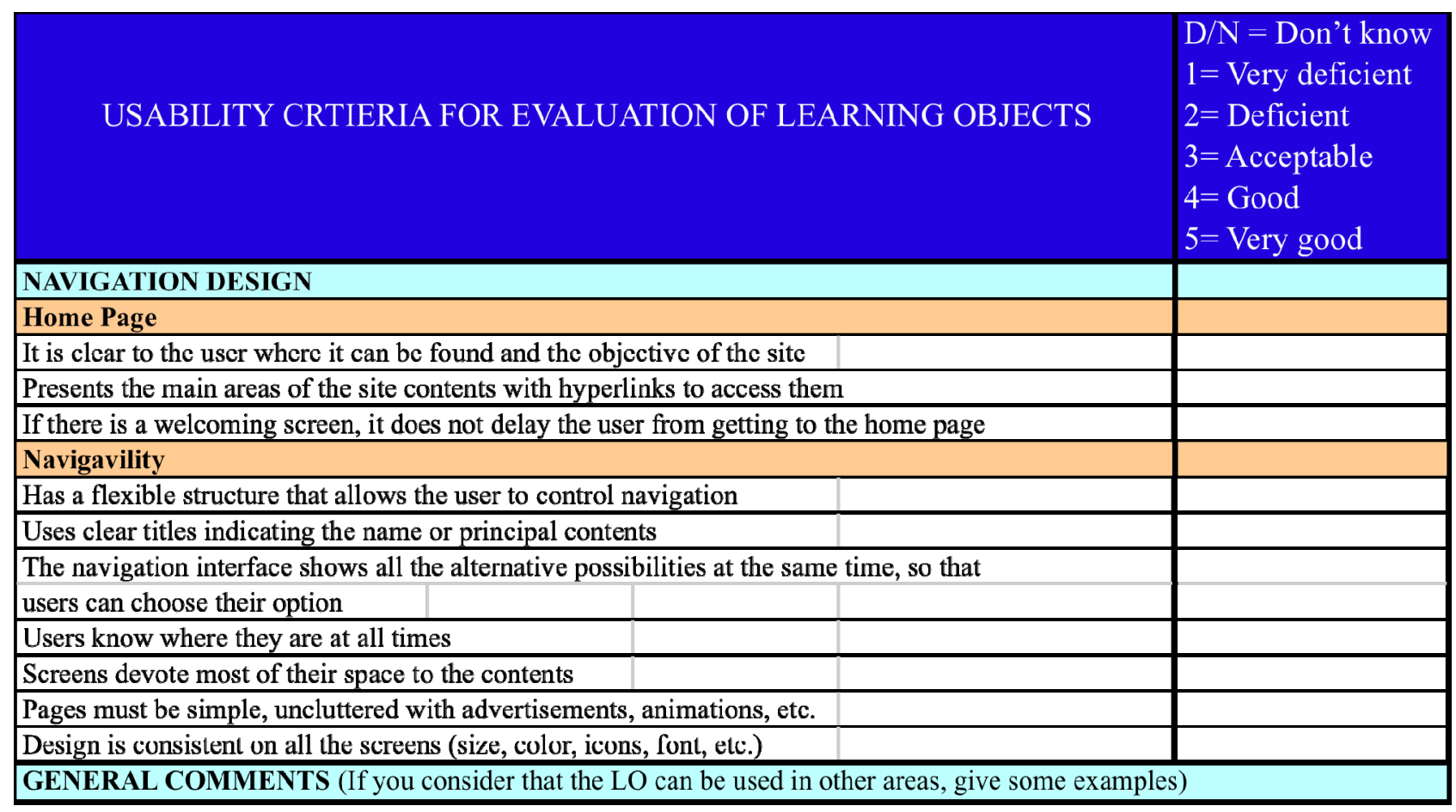

Figure 4. Navigation-Design category for evaluating LOs 


\section{HEODAR INTEGRATION INTO MOODLE}

Based on the idea of constructivist learning where the exchange of information and feedback from it are the basis for the creation of new knowledge, we present the results of the evaluation of the HEODAR tool mentioned and explained above as a mechanism for contributing new information about the assessment of learning objects, thus providing important information for both tutors and students.

The Moodle platform is a software package designed to help the teacher easily create online courses. This tool has been selected for its characteristic ease of updating and its modular design, ideal characteristics for this proposal. Moreover, the Moodle platform promotes a social constructivist pedagogy, that is, activities that facilitate interaction, collaboration and cooperation. This aspect is important for LO management since it is not enough just to design this type of activity; the platform should also facilitate its development.

Furthermore, Moodle is a very adaptable platform (among other features, which make it stand out it over the others) [3] [5] and is a free and open source, and thus can be modified allowing the integration of HEODAR.

In this way, taking as a basis each user's role in the platform, we would add, as shown in Figure 5, an activity only for "teachers" and "non-editing teacher" (which are two of the 7 possible roles in the platform), from which they can access the details of the assessments, see the list of evaluators, as well as comments from them; to do this, we change mainly the tables "_modules", “_role_capabilities," among others, and create a “_scorm_heodar” table.

"_scorm_heodar" will be used to store and view the results of the different assessments of SCORM / AICC objects, taking as fields the object identifier, the evaluation obtained, the evaluator, and a comment.

As we can see in Figure 6, the result of consulting this table will be shown on the page that lists the learning objects of each course; these ratings can be viewed by any user of the learning platform, providing feedback between designers of learning objects, teachers, and / or experts, thus enabling their continuous improvement.

The representation uses a 5-star rating from 1 to 5 , filled in depending on the case, either by values or weighted values. The LO assessment, as shown in Figure 6 , is divided into three parts: 1 is the representation of the average of the results of all assessments made of the LO, this is the LO assessment; 2 represents the value multiplied by the percentage of teachers who have evaluated the LO with respect to the total number of teachers, resulting in the weighted assessment, and finally 3 is the percentage of teachers who have evaluated the LO with respect to the total number of teachers.

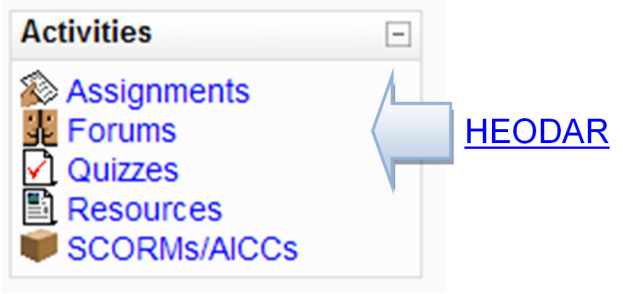

Figure 5. HEODAR integration into Moodle

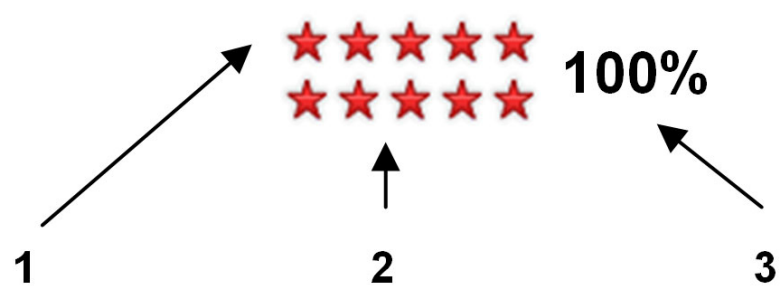

Figure 6. HEODAR representation

\section{CONCLUSIONS}

In this article we have presented a proposal for incorporating the assessment tool HEODAR so that it can be used in practice by experts to assess LOs and display the results of other assessments. It is thus addressed to providing experts with information about the LO's quality from various points of view and to use that knowledge to improve LO quality.

Experts who have validated each of the criteria presented in four categories have previously assessed the tool. Thus, the tool has a wide variety of criteria that can be assessed by specialists in technical and pedagogical aspects. The range of proposed assessment has welldefined indicators, which permit specific knowledge of the type of LO quality. Moreover, the ranking methodology suggested considers not only the average score obtained by an LO, but also one that is weighted by the number of teachers or experts who have assessed the tool and furthermore provides the percentage of teachers who have assessed the LOs in relation to the total percentage, so the final quality assessment becomes more reliable in that it considers the number of assessments.

Importantly, this proposal seeks to exploit the facilities presented by the Moodle open source tool, which allows us to make a specific proposal on how to modify tables to incorporate an assessment tool such as HEODAR.

As to future work, we plan to implement this proposal to provide specific data that can be analyzed. We furthermore seek to adapt the criteria for the assessment tool for users of LOs, so that upon using them they can provide valuable information in order to continually improve the quality of LOs.

\section{REFERENCES}

[1] P. Avgeriou, S. Retails and M. Skordalakis, "An architecture for open learning management systems". En Y. Manolopoulos, S. Evripidou, A.C. Kakas (Eds.) Advances in Informatics. Proceedings of the 8th Panhellenis Conference on Informatics, PCI 2001 Revised Selected Papers. Lectures Notes in Computer Science. LNCS 2563. Berlin: Springer Verlag, 2003. pp.183-200.

[2] K. Braun, M. Gadney, H. Matthew, A. Roselli, D. Synstelien, T. Walter and D. Wertheimer, "Usabilidad". Ediciones Anaya Multimedia Madrid, 2003.

[3] S. Graf, B. List, “An evaluation of open source e-learning platforms stressing adaptation issues. Advanced Learning Technologies”, ICALT 2005. Fifth IEEE International Conference on 5-8 July 2005 Page(s):163 - 165.

[4] IEEE Standard for Learning Object Metadata: ANSI/IEEE, 2002. http://ltsc.ieee.org/wg12/

[5] Y. Ohta, H. Nakano, K. Suzuki, T. Kiyan, T. Shimizu, C. Noguchi, T. Kita, H. Akiyama, "Practical study of instructional environments for lifelong e-learning, Information Technology Based Higher Education and Training”, 2005. ITHET 2005. 6th 
International Conference on 7-9 July 2005 Page(s):T4B/6 T4B11.

[6] T. A. Powell, "Diseño de Sitios Web: Manual de referencia”. Madrid: McGraw-Hill, 2001

[7] M. J. Rosenberg, "E-learning. Strategies for delivering knowledge in the digital age”. Bogotá: Mc Graw Hill, 2001.

[8] E. M. Morales, F. J. García and Á. Barrón, "LOs Instructional Design based on an Ontological Model to Improve their Quality,” in Proceedings of the 8th International Symposium on Computers in Education, SIIE'06. León, Spain, October 24th - 26th , 2006. Vol. 1. Pages 441-448. ISBN Obra completa 84-9773-303-7. ISBN Vol. 1 84-9773-301-0.

[9] E. M. Morales, F. J. García and Á. Barrón, “Key Issues for Learning Objects Evaluation,” in 9th International Conference on Enterprise Information Systems. Funchal, Madeira, 12 al 16 de Junio, 2007. ICEIS'07.

[10] E. M. Morales, F. J. García and Á. Barrón. 2008, “An Evaluation Instrument for Learning Object Quality and Management,” in 10th International Conference on Enterprise Information Systems. (Barcelona, España, 12 al 16 de Junio, 2008). ICEIS'08. INSTICC Press. ISBN obra completa 978-972-8865-91-7. http://www.iceis.org

[11] E. M. Morales, F. J. García and Á. Barrón, “Análisis comparativo de instrumentos de evaluación de Objetos de Aprendizaje”. Actas del V Simposio Pluridisciplinar sobre Diseño y Evaluación de Contenidos Educativos Reutilizables. Salamanca, España, 20 al 21 de Octubre, 2008. SPDECE’08. En prensa.

[12] F. Moreno and M. Bailly-Baillière, "Diseño instructivo de la formación on-line.” Aproximación metodológica a la elaboración de contenidos, Editorial Ariel Educación, 2002.
[13] J. Nielsen, J. “Usabilidad Diseño de Sitios Web”. Prentice Hall PTR, 2000.

\section{AUTHORS}

E. M. Morales Morgado is with the "Virtual University" project at the University of Salamanca, Spain, Calle Fonseca, No2, Salamanca. CP 37002 SPAIN (email: erlamorales@usal.es).

D.A Gómez Aguilar is a member of the research GRoup in Visual Analytics and Information Visualization (VisUsal) at the University of Salamanca, Spain. Plaza de los Caídos, S/N CP 37008, Salamanca SPAIN. (e-mail: dialgoag@usal.es).

F. J. García Peñalvo is with the Computer Science Department at the University of Salamanca, Spain. Plaza de los Caídos, S/N CP 37008, Salamanca SPAIN. (e-mail: fgarcia@usal.es).

R. Therón Sánchez is with the Computer Science Department at the University of Salamanca, CP 37008 SPAIN, (e-mail: theron@usal.es).

This article was modified from a presentation at $\mathrm{X}$ International Symposium on Computers in Education (SIIE2008) 1st-3rd October 2008, Salamanca, Spain. Manuscript received 09 October 2005. Published as submitted by the authors. 